\title{
Selective processing of drug cues in heroin dependence
}

Citation for published version (APA):

Franken, I., L.Y., K., Wiers, R. W., \& Jansen, A. (2000). Selective processing of drug cues in heroin dependence. Journal of Psychopharmacology, 14(4), 395-400.

https://doi.org/10.1177/026988110001400408

Document status and date:

Published: 01/01/2000

DOI:

10.1177/026988110001400408

Document Version:

Publisher's PDF, also known as Version of record

Document license:

Taverne

Please check the document version of this publication:

- A submitted manuscript is the version of the article upon submission and before peer-review. There can be important differences between the submitted version and the official published version of record.

People interested in the research are advised to contact the author for the final version of the publication, or visit the DOI to the publisher's website.

- The final author version and the galley proof are versions of the publication after peer review.

- The final published version features the final layout of the paper including the volume, issue and page numbers.

Link to publication

\footnotetext{
General rights rights.

- You may freely distribute the URL identifying the publication in the public portal. please follow below link for the End User Agreement:

www.umlib.nl/taverne-license

Take down policy

If you believe that this document breaches copyright please contact us at:

repository@maastrichtuniversity.nl

providing details and we will investigate your claim.
}

Copyright and moral rights for the publications made accessible in the public portal are retained by the authors and/or other copyright owners and it is a condition of accessing publications that users recognise and abide by the legal requirements associated with these

- Users may download and print one copy of any publication from the public portal for the purpose of private study or research.

- You may not further distribute the material or use it for any profit-making activity or commercial gain

If the publication is distributed under the terms of Article $25 \mathrm{fa}$ of the Dutch Copyright Act, indicated by the "Taverne" license above, 


\title{
Selective cognitive processing of drug cues in heroin dependence
}

\author{
Ingmar H. A. Franken1, Linda Y. Kroon1, Reinout W. Wiers'2 and Anita Jansen² \\ 1Parnassia Addiction Research Centre (PARC), ${ }^{2}$ Department of Psychology, University of Maastricht, The Netherlands
}

Previous studies provide evidence for the selective processing of disorder related stimuli on anxiety, depression, and eating disorders. There exist some preliminary indications that selective processing of drug cues may be involved in drug craving and relapse that deserve further investigation. In order to investigate the role of processing bias in an abnormal motivational system, the attentional bias for drug related stimuli was studied in a heroin dependent population. Heroin dependent participants $(n=21)$ and control participants $(n=30)$ performed a supra- and subliminal heroin Stroop task and heroin craving was assessed. Heroin dependent participants showed a considerable attentional bias for supraliminally presented heroin cues. However, there was no evidence for a preattentive bias on the subliminal presented cues. Reaction time on heroin cues was significantly predicted by heroin craving-levels. Results indicate that selective processing may be related to motivational induced states in general. The finding are discussed in the context of selective information processing in general psychopathology and in motivational processes as addiction specifically.

Key words: addiction; attentional bias; cognitive processing; craving; motivational processes

\section{Introduction}

In recent cognitive theories of psychopathology, the processing of information and its relation to dysfunctional schematics (Beck and Clark, 1997) has received extensive attention. Information processing and its contribution to psychopathology has been studied in several psychiatric disorders, such as obsessivecompulsive disorder (Lavy et al., 1993), phobia (Merckelbach et al., 1996; van den Hout et al., 1997), post-traumatic stress disorder (McNally et al., 1996) and depression (Mogg and Bradley, 1998). In the field of experimental psychopathology, theories on bias in selective attention towards emotional stimuli have been put forward in order to explain the origin and maintenance of abnormal psychological states (Williams et al., 1996). The brain's defensive system in relation to threat stimuli has been studied extensively, and attentional bias for this type of stimuli has been found in various types of anxiety disorders (Mogg and Bradley, 1998). For example, phobic patients have difficulties in shifting attention away from fear-related stimuli in presence of competing stimuli. This bias can be characterized as an increase in preoccupation and sensitivity to stimuli that are related to the specific type of psychopathology. Attentional bias for disorder related stimuli has been studied by attentional tests such as the Emotional Stroop Task (Williams et al., 1996) and dot probe tasks (Posner, 1980). In addition to difficulties with shifting attention away from fearful cues in anxiety patients, the anxious patient will notice a disorderrelated stimulus more quickly than a non-anxious individual will. This preconscious bias is experimentally studied by the same tests as attentional bias, however, cues are presented below perceptual threshold (subliminal), resulting in subliminal dot-probe tasks
(Mogg et al., 1995) or the subliminal Emotional Stroop Task (van den Hout et al., 1997). In studies on anxiety disorders, it is repeatedly demonstrated that phobic subjects make attentional shifts towards a subliminally presented disorder related stimulus (Mogg et al., 1995).

As with fearful stimuli, attention is automatically directed to intrinsically appetitive cues (Schupp et al., 1997) in normal states. The appetitive system includes approach, hunger, sexual and nurturing behaviour (Lang et al., 1998b). In addition to normal adaptive directing of attention towards appetitive cues such as in states of hunger, it would be useful to study selective processing in abnormal motivational states such as addictive behaviours. Addiction can be regarded as an abnormal appetitive and motivational state in which the appetitive system is disordered. When appetite becomes greater than warranted by the situation, an addictive disorder exists (analogous to fear; LeDoux, 1998). Although attentional processes may be of major value in explaining excessive craving and compulsive drug seeking by providing essential links between psychological and biological processes, research on attentional bias in abnormal appetitive states is restricted to a few studies on gambling (McCusker and Gettings, 1997), eating disorders (Cooper et al., 1992), alcohol dependence (Johnsen et al., 1994; Stetter et al., 1995; Bauer and Cox, 1998; Cox et al., 1999), nicotine dependence (Gross et al., 1993; Johnsen et al., 1997), and cocaine dependence (Rosse et al., 1997). These studies report an attentional bias of addicted subjects on disorder related material. Studies on the role of preattentional processes in motivational induced bias are scarce. A recent study on selective attention for food stimuli in states of hunger, no preattentional bias was observed (Mogg et al., 1998). 
Craving can be regarded as the emotional representation of an appetitive state. In most current conceptualizations of drug dependence, such as ICD-10 and DSM-IV, subjective craving is regarded as a central phenomenon, contributing to the continuation of drug use in active addicts and the occurrence of relapse in detoxified addicts (APA, 1994). There is evidence that craving for psychoactive substances disrupts attentional performance (Sayette and Hufford, 1994; Sayette et al., 1994; Cepeda-Benito and Tiffany, 1996).

Several issues concerning the selective processing of addiction related cues have not been studied before. Although the findings of several studies suggest that attentional bias for addiction related stimuli is a general feature for motivational states, it has not been investigated before in relation to heroin dependence. Furthermore, it has been suggested that the fast processing of arousing input may be a general phenomenon that occurs for both appetitive and aversive cues (Lang et al., 1998a). Hitherto, research on the preattentive processing of addiction related cues has not been conducted (see also Weinstein et al., 1998). In addition, the relation between craving and the processing of appetitive cues has been suggested to be useful in cognitive theories of addictive disorders (Franken et al., 2000) and needs further investigation.

In order to address the topics mentioned above, three specific hypotheses are addressed in the present study. First, the explicit emotional Stroop task (Williams et al., 1996) is able to differentiate between a group of individuals with heroin dependency and a normal control group. The emotional Stroop paradigm provides a reliable instrument (Williams et al., 1996) for assessing attentional bias. A second hypothesis, in addition to an explicit attentional bias, is that implicit drug information processing in heroin dependency is biased compared to a normal control group. Third, there exists in individuals with a heroin dependency diagnosis a positive relation between the amount of craving and cognitive performance. The amount of interference within the heroin group is correlated with craving in the past week as measured by the Obsessive Compulsive Drug Use Scale version Heroin (OCDUSheroin).

\section{Methods}

\section{Participants}

The experiment was conducted in two groups: a group of abstinent heroin dependent patients (heroin group, $n=21$ ) and a non-heroin dependent control group (controls, $n=31$ ). All participants in the heroin group were inpatients from a clinical treatment centre for drug dependency (Addiction Unit of the Parnassia Psychiatric Centre, the Hague, Netherlands), and met the DSM-IV criteria (APA, 1994) for heroin dependence. All the participants in the heroin group had abstained from using any psychoactive substance for at least 1 week and received no medication. Both drug treatment and study participation were voluntary. Participants in the control group were recruited among clinical and administrative staff of the clinic and were likely to be familiar with drug related words. Exclusion criterion for the control group was lifetime use of heroin. For both groups, participants with severe psychopathology, colour blindness and (non-corrected) defective vision were excluded. The two groups were matched as closely as possible with respect to age, education and gender. The percentages of male participants in the heroin and control group were $71.4 \%$ and
$83.3 \%$, respectively. Mean age of the heroin and control group was 31.5 and 34.8 years, respectively. For the heroin group, the mean self-reported duration of heroin dependence was 93.9 months $(\mathrm{SD}=84.0)$. Mean time of current abstinence was 9 weeks $(\mathrm{SD}=8.94)$. Patients received a financial compensation (equivalent of US\$7) for participation.

\section{Craving measurements}

The Obsessive Compulsive Drug Use Scale (OCDUS-heroin version, Franken et al., submitted) was used as a cognitive correlate of craving in the past week. The OCDUS, a 14-item selfrating questionnaire (five ordinal response categories), is constructed analogue to the Obsessive Compulsive Drinking Scale (OCDS) (Anton et al., 1996). Similar to the OCDS, the OCDUS consists of two subscales. First, the obsessive subscale (OB), which measures the frequency of thoughts concerning heroin, the ability to resist the thoughts and the emotional distress resulting from these thoughts and, second, the compulsive subscale (CP), measuring frequency of drug use, compulsive drive to use heroin and the experienced control over heroin use. The sum of both scales results in a total score (TOT), which can be understood as a multidimensional measure of cognitive aspects of craving (Anton et al., 1996; Moak et al., 1998). From an initial validation study, it was found that OCDUS hold satisfactory psychometric properties (Cronbach's alpha OB-scale $=0.85 ; \mathrm{CP}$-scale $=0.82$; factor structure corresponds with the two scales). In a validation study of the original OCDS, the authors concluded that the OCDS is a reliable and valid self-rating instrument for the measurement of dimensions of alcohol craving (Anton et al., 1996). In a previous study with the present OCDUS-cocaine version, it was found that scores on this questionnaire were correlated to reaction times on cocaine related cues in cocaine dependent patients (Franken et al., 2000).

A single-item visual analog craving scale (VAS craving) was administered in order to measure pre- and post-experiment craving. Although there are some methodological difficulties using a single item craving VAS in terms of validity and reliability (Tiffany, 1992), a VAS can quickly be administred between tasks. The subject was asked to indicate, on a $100 \mathrm{~mm}$ scale, how much craving for heroin they experienced at that moment. In contrast to the OCDUS, which measures more stable aspects of craving (past week), the VAS measures cue induced craving (at the moment) which can vary from moment to moment.

\section{Apparatus and materials}

All stimulus material was presented on an IBM G50 monitor, controlled by an IBM P-100 PC. The presentation of the stimuli was programmed in EXPE language (Pallier et al., 1997). A microphone was placed in front of the subject and was connected with a voice key. Reaction time was measured by the voice key, which stopped the computer clock at the nearest ms when a verbal reaction was detected.

For both Stroop tasks, stimulus words were presented in $13 \mathrm{~mm}$ uppercase letters. Neutral and heroin words were presented in random order to prevent rumination effect observed in blocked (by category) presentation (Holle et al., 1997). Stroop tasks consisted of 10 heroin-related words (Dutch equivalent of score, flash, smack, dope, dealer, junk, shot, ball, heroin, inhale) and 10 neutral, transport-related words (Dutch equivalent of pilot, ticket, crosswalk, train, vehicle, bike, scooter, trolley, asphalt, gasoline). 
Neutral words were matched for the number of letters and syllables, but not for the frequency of use in Dutch language. No data concerning word use frequency of Dutch heroin related words are known, which are for the most part slang. However, previous studies indicate that word frequency has little effect on attentional tasks (Mogg and Marden, 1990; McNally et al., 1990). Drug words were chosen from lists of words that were provided by three local drug-counsellors. Words were selected for unambiguity (as far as possible) and familiarity among drug users and drug-counsellors. Each word was presented 10 times in a random order resulting in 100 neutral and 100 heroin words in total. Masked and unmasked words were presented in the colors green, yellow, blue, or red. In the subliminal task, masked words and masks had identical colors.

\section{Procedure}

After obtaining written informed consent, participants completed a short questionnaire including questions about age, education, weeks in treatment, and duration of substance abuse. In addition, the OCDUS questionnaire and a craving-VAS were completed by the heroin group. All participants were subsequently given a Masked Stroop colour-naming task (Masked Stroop), followed by a second craving-VAS for the heroin group. After this procedure, all participants performed an awareness check task. Finally, participants were given an unmasked Stroop colour naming task (Unmasked Stroop), followed by the third craving-VAS for the heroin group.

In the Masked Stroop task, a stimulus word was presented for $28 \mathrm{~ms}$ in one of the four colors and immediately replaced by a random letter mask (e.g. JKWK) in the same colour. The mask remained on the screen until vocal response, with a maximum of $3000 \mathrm{~ms}$. In the Unmasked Stroop Task, a stimulus word in one of the four colors was presented on the screen and remained on the screen until response (maximum $3000 \mathrm{~ms}$ ). In both tasks, participants were instructed to name the colour of the presented target word as quickly as possible. The order of presentation was random, with the restriction that a specific word category (heroin versus neutral) was not presented more than four consecutive times. In both masked and unmasked Stroop, the inter-trial interval was set at $1000 \mathrm{~ms}$.

To assure that participants were not aware of the content of the masked stimulus, words were presented below perception threshold (subliminally). Previous studies demonstrate that words presented for $28 \mathrm{~ms}$ are generally not consciously identified by the subject (Bradley et al., 1996). To verify this, an awareness check was carried out for each subject. This check consisted of a forcedchoice lexical decision task in which 15 words and 15 non-words were presented subliminally $(28 \mathrm{~ms})$. After presentation of this word or non-word, it was immediately replaced by a random letter mask. The subject was asked to indicate verbally whether the word presented before the mask was a word or a non-word.

\section{Results}

\section{Participants characteristics}

Age, $t(49)=-1.73, p=0.090$, and gender, chi-squared $=1.03$, d.f. $=1, P=0.309$, distribution were not different for the two groups. Differences were found in education, control participants had a higher level of education than heroin participants, chisquared $=13.43$, d.f. $=2, p<0.01$. Additional analysis showed that, for both groups, level of education was not significantly correlated with any of the dependent variables. Consequently, the level of education was not added as covariate in the analysis of variance.

\section{Stroop tasks}

Kemp-Wheeler and Hill (1988) suggested that the probability of making a correct response should fall within the $95 \%$ confidence limits about the chance expectation of 0.50 . In our manipulation check task, two control participants identified the words/non-words correctly above chance level, indicating that for these participants the subliminal words were above subjective awareness threshold. In accordance with the criteria of Kemp-Wheeler and Hill, these two participants were excluded from the analysis. This analysis shows that included participants were, as expected, unaware of the lexical content of the masked stimuli. All response latencies less than $200 \mathrm{~ms}$ or greater than $3000 \mathrm{~ms}$ were omitted.

A $2 \times 2$ mixed design analysis of variance (ANOVA) of reaction time (RT) on masked and unmasked Stroop, with Group (heroin versus control) as between subjects variable and Cue Type (heroin versus neutral word) as within participants variable. For the RTs on the unmasked Stroop, a significant Cue Type-Group interaction was observed $[F(1,49)=15.12, p<0.001]$. Cell means (Table 1$)$ indicated that this effect has to be attributed to greater RTs for the heroin group on heroin-related words. Furthermore, ANOVA analysis showed significant higher overall RTs for the heroin group compared to the control group $[F(1,49)=31.99, p<0.001]$.

Table 1 Verbal reaction times (ms)

\begin{tabular}{cccccc}
\hline & \multicolumn{2}{c}{ Heroin group } & & \multicolumn{2}{c}{ Control group } \\
\cline { 2 - 3 } \cline { 5 - 6 } & $\mathrm{M}$ & $\mathrm{SD}$ & & $\mathrm{M}$ & $\mathrm{SD}$ \\
\hline Masked stroop & & & & \\
Heroin cues & 703.46 & 163.71 & & 629.01 & 81.18 \\
Neutral cues & 708.93 & 190.24 & 624.79 & 75.90 \\
Unmasked stroop & & & & \\
Heroin cues & 896.42 & 149.53 & 688.66 & 84.30 \\
Neutral cues & 832.62 & 144.02 & 681.92 & 86.61 \\
\hline
\end{tabular}

For RTs on the masked Stroop, no Cue Type-Group interaction effect was observed $[F(1,49)=0.60, p=0.44]$. This indicates that RTs on masked heroin cues were not different for the heroin and control group. As with the unmasked Stroop, higher overall RTs for the heroin group were observed compared to the control group $[F(1,49)=4.46, p<0.04]$.

\section{Craving}

Mean pre-experiment craving was $13.8(\mathrm{SD}=16.8)$, mean post masked Stroop craving score was $7.19(\mathrm{SD}=10.7)$, and mean post unmasked Stroop craving score was 15.2 ( $S D=20.2$ ). Oneway repeated measurement ANOVA with pairwise comparison (Bonferonni adjusted) showed significant differences between post masked Stroop and post unmasked Stroop craving scores $(p<0.05)$.

A series of correlations was computed between RTs on neutral versus heroin cues, interference scores and craving scores (VAS and OCDUS). The correlation between the OCDUS and masked 
Table 2 Correlations between craving scores, reaction times and interference scores of the heroin group

\begin{tabular}{lccccccc}
\hline & \multicolumn{3}{c}{ Unmasked stroop } & & \multicolumn{3}{c}{ Masked stroop } \\
\cline { 2 - 3 } Craving & RT-cue & RT-neutral & Interfer. & & RT-cue & RT-neutral & Interfer. \\
\hline OCDUS total & $0.50^{*}$ & $0.50^{*}$ & 0.03 & & $0.46^{*}$ & 0.35 & 0.13 \\
Baseline VAS & $0.48^{*}$ & 0.33 & 0.32 & & 0.14 & 0.08 & 0.13 \\
Post-masked stroop & $0.48^{*}$ & 0.41 & 0.15 & & 0.28 & 0.23 & 0.05 \\
VAS & & & & & & & \\
Post-unmasked & $0.59^{* *}$ & $0.50^{*}$ & 0.23 & & 0.27 & 0.27 & -0.12 \\
stroop VAS & & & & & & &
\end{tabular}

$* p<0.05, * * p<0.01$.

Stroop interference was significant. All correlations between craving measures and RTs are shown in Table 2.

As presented in Table 2, supraliminally presented neutral cues are correlated with craving scores as well as with heroin cues. An additional analysis was employed in order to control for priming effects. A priming effect may be created when a subject's attention on a neutral cue is biased as result of a preceding heroin cue. RTs on the first and fourth neutral cue following a heroin cue were compared using a paired $t$-test. Data examination resulted in 41 trials with four consecutive neutral cue presentations. Results indicated that the RTs on the first $(M=834 \mathrm{~ms})$ of four consecutive neutral words was significant slower than the RTs on the fourth $(M=712 \mathrm{~ms})$ neutral word $[t(40)=5.27, p<0.001]$. To control whether this priming effect is also present in heroin cues, the same analysis was performed on four consecutively presented heroin cues (41 trials). No difference was found between the RTs on the first $(M=829 \mathrm{~ms})$ and fourth $(M=941 \mathrm{~ms})$ heroin cue $[t(40)=-1.83, p=0.07]$. In order to control for this priming effect, additional analysis on the correlations between Post unmasked Stroop VAS and RTs on the third consecutive neutral cue were performed. This correlation was not significant $[r=0.14, p=0.53]$. However, the correlation between the OCDUS score and the third consecutive neutral cue remained significant $[r=0.54, p=0.01]$.

In addition, extra-hypothetical correlations were calculated between explicit attentional bias and history of drug use. No significant correlation was found between addiction duration with interference $[r=0.08, p=0.74]$ and time in treatment with interference $[r=0.19, p=0.42]$. However, a significant correlation was found between number of previous treatments and unmasked Stroop interference $[r=0.52, p<0.05]$. No significant correlations were found between preattentive bias and drug history.

\section{Discussion}

The present study shows for the first time that attentional processes in heroin dependence are biased. Heroin dependent patients process heroin related cues selectively, that is more attentional resources are directed towards heroin cues compared to neutral cues. The RT on drug related cues was found to be correlated with self-reported craving for heroin. In addition, we found no evidence for the existence of a preattentional bias on subliminally presented stimuli in this population. However, for one of the craving measures, the OCDUS, a significant relation was observed with RTs on subliminal presented drug cues.

The attentional bias found on supraliminally presented cues corresponds with other studies addressing cognitive bias in the processing of appetitive cues (Gross et al., 1993; Lavy and van den Hout, 1993; Mogg et al., 1998). This finding indicates that attentional bias is not exclusively a feature of mood or anxiety disorders, but also exists in motivational states observed in addictive disorders. This finding supports the view of Lang et al. (1997) that attention is always automatically directed to cues that have motivational significance. The behavioural response in these appetitive motivational states is opposite to the response observed in anxiety disorders. In addictive disorders, craving represents a feeling of wanting to approach a pleasant stimulus (e.g. heroin). In contrast, in anxiety disorders, patients want to avoid an aversive stimulus (e.g. a spider). As with physiological measures such as Event Related Potentials (Schupp et al., 1997), the occurrence of attentional bias can reflect the activation of both the approach as well as the avoidance system. The Stroop task can actually make no statement about motivational valence. From the learning literature, it is clear that drug cues may also hold dysphoric or withdrawal properties (O'Brien et al., 1998). The correlations found in the present study between the craving (wanting) and attentional bias, suggest an activation of the approach system, not the avoidance system. More research is needed in order to clarify the motivational valence of drug cues.

Craving was found to be related to increased RT latencies on supraliminally presented drug cues. Some authors (Lavy and van den Hout, 1993; Overduin et al., 1995) suggest that attentional bias for appetitive cues may represent an urge to act. Although lack of behavioural measures in the present study prevents drawing conclusions that would corroborate this suggestion, the observed relation between different craving measures and RTs on heroin cues provides some support for this hypothesis.

In addition to heroin cues, craving was also related to RTs on neutral cues. This latter finding can partly be explained by the observed priming effects. When a neutral cue is preceded by drug cues, RT on the neutral cue is prolonged. When controlled for this priming effect, there is no longer a correlation between neutral cues and post-task craving. However, the relation between craving in the past week (OCDUS) and RTs on neutral cues is preserved. This suggests that more stable aspects of craving (past week), in contrast to craving directly triggered by cues, is related to prolonged RTs on neutral cues. Because differences between these two aspects of craving are theoretically important, further study on these preliminary findings is needed.

In contrast to the attentional bias, we found no evidence for a preattentive bias for drug related cues in heroin dependence. The suggestion of Lang et al. (1998a), that the fast processing of 
arousing input may be a general phenomenon that occurs for both appetitive and aversive cues, could not be confirmed in the present study. No group difference between the heroin group (for which heroin cues have conditioned appetitive properties) and control group (for which heroin cues have neutral properties) on the processing of subliminal heroin cues was observed. Our findings support the conclusion of Mogg et al. (1998), that a bias in preattentive processing may be a specific feature of anxiety, and is not present in appetitive motivational states. A possible explanation for this finding has been provided by the evolutionary preparedness theory of Öhman (1993). According to this theory, fear-relevant stimuli are detected very early because of an evolutionary preparedness. An early detection mechanism for these stimuli is effective in locating threats in the surrounding world and necessary for survival (Öhman, 1997). However, for appetitive stimuli, such a evolutionary preparedness mechanism is not required in order to survive.

An alternative explanation for the absence of a preattentive bias is that the presentation time of the subliminal cues $(28 \mathrm{~ms})$ may have been too long. Typically, a preattentive bias on threat faces is only evident when stimuli are presented at $17 \mathrm{~ms}$ duration. However, when the same presentation is at $34 \mathrm{~ms}$ stimulus duration, preattentive bias is not observed (Mogg and Bradley, 1998). It could be argued that preconscious effects in heroin addiction may also be dependent on exactly chosen stimulus duration. In addition, from the RT results on the Stroop tasks, it can be observed that the subliminal task was easier than the supraliminal task. It may be that the easier task may have been less discriminating, and less likely to reveal group differences as function of cue type, than the more difficult supraliminal task. Finally, the lack of findings on the subliminal task may reflect an overall dysfunctional cognitive ability of the heroin dependent subjects. Clearly, the influence of preattentive processes in the processing of motivational cues needs further research in a larger sample size or with a more discriminating subliminal task.

Although no preattentional bias is found for drug cues in heroin dependence, a significant relation was found between craving and RTs on masked heroin cues. This finding may indicate that individual differences within the heroin group are present. Although no firm conclusions can be drawn because of the nonsignificant group $\times$ word type effect on the Masked Stroop tasks, it may be that a subgroup of heroin dependent patients, characterized by more frequently occurring obsessive heroin related thoughts and craving, is biased in the processing of subliminal heroin cues. Individual differences in these characteristics on information processing are also found in a previous study on cocaine dependent patients (Franken et al., 2000). In this latter study, in which a dotprobe task was employed, the correlation between RT and craving was only found significant in the short cue presentation time $(100 \mathrm{~ms})$, not in the long presentation time $(500 \mathrm{~ms})$. These preliminary findings should be examined in further research.

As discussed above, the relation between craving and prolonged RT on primary (colour naming) task in the presence of an additionally presented drug cue is unclear. Juliano and Brandon (1998) found indications that prolonged RTs do not exclusively reflect cognitive processing of smoking urges, but also reflects cognitive attempts to cope with these urges. In addition, drug abuse patients may devote cognitive resources towards inhibiting the preparatory responses (Tiffany, 1990). The present study provides preliminary indications that, in a subpopulation of heroin dependent patients characterized as high cravers, prolonged RT is not associated with the directing of limited capacity resources towards inhibiting the preparatory response. If words are not consciously perceived, it is unlikely that these subliminal presented cues trigger coping strategies. In addition, our data suggest that the subliminal presented words do not result in increased craving.

The present study indicates that in addition to subjectively experienced craving, cognitive bias is present in addictive behaviour, thus stressing the need for additional therapeutic interventions aimed at these cognitive processes. The effectiveness of currently applied cognitive interventions aimed at self-regulation may be limited by the 'occupation' of the subject's attentional capacity by drug-related stimuli. When the heroin dependent subject is gripped by craving and experiences a high urge to act, the subject will not be impeded by the memory of negative consequences of drug taking (Leshner, 1999). Information processing models of addiction may contribute to our current understanding of craving and continued drug use and relapse, and may provide important clues for the future development of treatment interventions. Recent addiction theories stress the importance of motivational properties of substances of abuse (Di Chiara, 1998) and the relationship between the addiction and neurobiological processes in the brain (e.g. Self, 1998; Wise, 1988). Craving and attentional processes may result from a common neural pathway. For example, Robinson and Berridge (1993) notice the relationship between addictive processes, the hypersensitivity of the mesolimbic dopaminergic system and the increased attention on drug cues. Furthermore, the findings of the present study may contribute to improvements in the assessment of craving. Similar to alcohol studies (e.g. Love et al., 1998), the assessment of self-reported craving has to be improved by future studies. Albeit, attentional bias may provide a more objective measure of an individual's drug approach tendency than selfreported craving (Rosse et al., 1997).

In general, it can be concluded that the abnormal information processing within the appetitive system (and its related disorders such as substance abuse, eating disorders, and gambling) needs further study. Given the high prevalence and distress caused by these disorders, it is striking that studies addressing the abnormal appetitive system are scarce, whereas considerable knowledge has been collected in recent decades on the abnormal fear/avoidance system (Lang et al., 1998a; LeDoux, 1998).

\section{Acknowledgement}

Preparation of this article was supported by a grant of the Dutch Organization for Scientific Research (NWO).

\section{Address for correspondence}

Ingmar H. A. Franken

Parnassia Research Centre

PO Box 53002

2505 AA The Hague

The Netherlands

Email: i.franken@parnassia.nl

\section{References}

Anton R F, Moak D H, Latham P K (1996) The obsessive compulsive drinking scale: a new method of assessing outcome in alcoholism treatment studies. Arch Gen Psychiatry 53: 225-231 
American Psychiatric Association (1994) Diagnostic and statistical manual of mental disorders, 4th edn, pp. 424-426. American Psychiatric Association, Washington, DC

Bauer D, Cox W M (1998) Alcohol-related words are distracting to both alcohol abusers and non-alcohol abusers in the Stroop colour-naming task. Addiction 93: 1539-1542

Beck A T, Clark D A (1997) An information processing model of anxiety: Automatic and strategic processes. Behav Res Ther 35: 49-58

Bradley B P, Mogg K, Millar N (1996) Implicit memory bias in clinical and non-clinical depression. Behav Res Ther 34: 865-879

Cepeda-Benito A, Tiffany $\mathrm{S} T$ (1996) The use of a dual-task procedure for the assessment of cognitive effort associated with cigarette craving. Psychopharmacol 127: 155-163

Cooper M J, Anastasiades P, Fairburn C G (1992) Selective processing of eating-, shape-, and weight-related words in persons with bulimia nervosa. J Abnorm Psychol 101: 352-355

Cox W M, Yeates G N, Regan C M (1999) Effects of alcohol cues on cognitive processing in heavy and light drinkers. Drug Alcohol Depend 55: 85-89

Di Chiara G (1998) A motivational learning hypothesis of the role of mesolimbic dopamine in compulsive drug use. J Psychopharmacol 12: 54-67

Franken I H A, Kroon L Y, Hendriks V M (2000) Influence of individual differences in craving and obsessive cocaine thoughts on attentional processes in cocaine abuse patients. Addict Behav 25: 99-102

Franken I H A, Hendriks V M, Van den Brink W (submitted) Initial validation of two opiate craving questionnaires: The Obssessive Compulsive Drug Use Scale (OCDUS) and the Desires for Drug Questionnaire (DDQ)

Gross T M, Jarvik M E, Rosenblatt M R (1993) Nicotine abstinence produces context-specific Stroop interference. Psychopharmacol 110: 333-336

Holle C, Neely J H, Heimberg R G (1997) The effects of blocked versus random presentation and semantic relatedness of stimulus words on response to a modified stroop task among social phobics. Cogn Ther Res 21: 681-697

Johnsen B H, Laberg J C, Cox W M, Vaksdal A, Hugdahl K (1994) Alcoholic subjects' attentional bias in processing of alcoholrelated words. Psychol Addict Behav 8: 111-115

Johnsen B H, Thayer J F, Laberg J C, Asbjornsen A E (1997) Attentional bias in active smokers, abstinent smokers, and nonsmokers. Addict Behav 22: 813-817

Juliano L M, Brandon T H (1998) Reactivity to instructed smoking availability and environmental cues: evidence with urge and reaction time. Exp Clin Psychopharmacol 6: 45-53

Kemp-Wheeler S M, Hill A B (1988) Semantic priming without awareness: some methodological considerations and replications. Q J Exp Psychol 40A: 671-692

Lang P J, Bradley M M, Cuthbert B N (1997) Motivated attention: Affect, activation, and action. In Lang PJ, Simons RF, Balaban $M$ (eds), Attention and orienting: sensory and motivational processes, pp. 477. Lawrence Erlbaum Associates Inc, New Jersey

Lang P J, Bradley M M, Cuthbert B N (1998a) Emotion, motivation, and anxiety: Brain mechanisms and psychophysiology. Biol Psychiatry 44: 1248-1263

Lang P J, Cuthbert B N, Bradley M M (1998b) Measuring emotion in therapy: Imagery, activation, and feeling. Behav Ther 29: 655-674

Lavy E H, van den Hout M A (1993) Attentional bias for appetitive cues: effects of fasting in normal subjects. Behav Cog Psychother 21: 297-310

Lavy E, van Oppen P, van den Hout M (1993) Selective processing of emotional information in obsessive compulsive disorder. Behav Res Ther 32: 243-246

LeDoux J (1998) Fear and the brain: where have we been, and where are we going? Biol Psychiatry 44: 1229-1238

Leshner A I (1999) Science is revolutionizing our view of addiction - and what to do about it. Am J Psychiatry 156: 1-3

Love A, James D, Willner P (1998) A comparison of two alcohol craving questionnaires. Addiction 93: 1091-1102

McCusker C G, Gettings B (1997) Automaticy of cognitive biases in addictive behaviours: further evidence with gamblers. Br J Clin Psychol 36: 543-554

McNally R J, Riemann B C, Kim E (1990) Selective processing of threat cues in panic disorder. Behav Res Ther 28: 407-412
McNally R J, Amir N, Lipke H J (1996) Subliminal processing of threat cues in posttraumatic stress disorder. J Anx Dis 10 115-128

Merckelbach H, de Jong P J, Muris P, van den Hout M A (1996) The etiology of specific phobias: a review. Clin Psychol Rev 16: 337-361

Moak D H, Anton R F, Latham P K (1998) Further validation of the obsessive-compulsive drinking scale (OCDS) - relationship to alcoholism severity. Am J Addict 7: 14-23

Mogg K, Bradley B P (1998) A cognitive-motivational analysis of anxiety. Behav Res Ther 36: 809-848

Mogg K, Marden B (1990) Processing of emotional information in anxious subjects. Br J Clin Psychol 29: 227-229

Mogg K, Bradley B P, Williams R (1995) Attentional bias in anxiety and depression - the role of awareness. Br J Clin Psychol 34: $17-36$

Mogg K, Bradley B P, Hyare H, Lee S (1998) Selective attention to food-related stimuli in hunger: Are attentional biases specific to emotional and psychopathological states, or are they also found in normal drive states? Behav Res Ther 36: 227-238

O'Brien C P, Childress A R, Ehrman R, Robbins S J (1998) Conditioning factors in drug abuse: can they explain compulsion. J Psychopharmacol 12: 15-22

Öhman A (1993) Fear and anxiety as emotional phenomena: clinical phenomenology, evolutionary perspectives, and information processing mechanisms. In Lewis M, Haviland JM (eds), Handbook of emotions. Guilford, New York

Öhman A (1997) As fast as the blink of an eye: evolutionairy prepardness for preattentive processing of threat. In Lang PJ, Simons RF, Balaban M (eds), Attention and orienting: sensory and motivational processes, pp. 477. Lawrence Erlbaum Associates Inc, New Jersey

Overduin J, Jansen A, Louwerse E (1995) Stroop interference and food intake. Int J Eat Disord 18: 277-285

Pallier C, Dupoux E, Jeannin X (1997) EXPE: an expandable programming language for on-line psychological experiments. Behav Res Methods Instrum Comput 29: 322-327

Posner M I (1980) Orienting of attention. Q J Exp Psychol 32: 3-25

Robinson T E, Berridge K C (1993) The neural basis of drug craving: An incentive-sensitization theory of addiction. Brain Res Rev 18: $247-291$

Rosse R B, Johri S, Kendrick K, Hess A L, Alim T N, Miller M M, Deutsch S I (1997) Preattentive and attentive eye movements during visual scanning of a cocaine cue: correlation with intensity of cocaine cravings. J Neuropsychiatr Clin Neurosci 9 91-93

Sayette M A, Hufford M R (1994) Effects of cue exposure and deprivation on cognitive resources in smokers. J Abnorm Psychol 103: 812-818

Sayette M A, Monti P M, Rohsenow D J, Gulliver S B, Colby S M, Sirota A D, Niaura R, Abrams D B (1994) The effects of cue exposure on reaction time in male alcoholics. J Stud Alcohol 55: 629-633

Schupp H T, Cuthbert B N, Bradley M M, Birbaumer N, Lang P J (1997) Pobe P3 and blinks: two measures of startle modulation. Psychophysiology 34: 1-6

Self D W (1998) Neural substrates of drug craving and relapse in drug addiction. Ann Med 30: 379-389

Stetter F, Ackerman K, Bizer A, Straube E R, Mann K (1995) Effects of disease-related cues in alcoholic inpatients: Results of a controlled 'alcohol Stroop' study. Alcohol Clin Exp Res 19: 593-599

Tiffany S T (1990) A cognitive model of drug urges and drug-use behavior: Role of automatic and nonautomatic processes. Psychol Rev 97: 147-168

Tiffany S T (1992) A critique of contemporary urge and craving research: methodological, psychometric, and theoretical issues. Special issue: irges and cravings. Adv Behav Res Ther 14: 123-139

van den Hout M, Tenney N, Huygens K, de Jong P (1997) Preconscious processing bias in specific phobia. Behav Res Ther 35: 29-34

Weinstein A, Feldtkeller B, Malizia A, Wilson S, Bailey J, Nutt D J (1998) Integrating the cognitive and physiological aspects of craving. J Psychopharmacol 12: 31-38

Williams J M G, Mathews A, MacLeod C (1996) The emotional Stroop task and psychopathology. Psychol Bull 120: 3-24

Wise R A (1988) The neurobiology of craving: Implications for the understanding and treatment of addiction. J Abnorm Psychol 97: 118-132 